\title{
Empirical Analysis of MACD Based on Cloud Computing of Listed Companies
}

\author{
Pin Wang ${ }^{1, a}$, Zhong-hua Ling ${ }^{1, b}$ and Hong $\mathrm{Li}^{2, \mathrm{c},{ }^{*}}$ \\ ${ }^{1}$ Mathematics and Information Science Department, Guangxi College of Education, Nanning \\ 530023, Guangxi, China \\ ${ }^{2}$ School of education Science, Guangxi normal college, Nanning 530023, Guangxi, China \\ a1040168586@qq.com, 'blzh771@163.com, C2291622035@qq.com \\ *Corresponding author: Hong LI
}

Keywords: Cloud computing, MACD, Empirical analysis.

\begin{abstract}
MACD (Moving Average Convergence and Divergence), as an expert system of software for securities trading, is tested by statistical and empirical analysis based on real data about cloud computing which are publicly available. To realize management objectives of annual net profit margin, rate of return and win rate, non-directional MACD indicators are empirically analyzed based on theories of mathematical statistics. In this expert system, annual rate of return and net profit margin are $102.08 \%$ and $102.07 \%$ of Shanghai Stock Exchange indexes respectively. An investment solution will be optional for investors who prefer making considerable profits and dare to take risks as long as their win rate is as high as $45.53 \%$ and their annual rate of return is 11.85 times the annual interest rate of bank deposits.
\end{abstract}

\section{Introduction}

As an approach to securities investments, technical analysis is performed to predict change tendencies of market prices by analyzing market behaviors. It focuses on drawing figures or graphs in a chronological order or establishing some index systems based on data about daily transactions in stock market, including price fluctuations, changes to trading volume and open interest. Then, analysis and research are performed based on these figures, graphs or index systems to forecast tendencies o stock prices. Computers are so popular that they can be used for analyzing securities and concluding transactions of all securities investors. At present, MACD is a common expert system of software for analyzing securities. Generally known as an index system, it is theoretically based on Dow Jones' "average cost concepts". For the management objectives of win rate, annual rate of return and net profit margin, data about listed companies' cloud computing were statistically tested and practicality of MACD was analyzed.

Proposed by Geral Appel in 1979 [1], MACD is calculated based on the difference between fast and slow exponential moving averages (EMAs). Here, "fast" and "slow" imply short-term and long-term EMAs respectively. 12-Day and 26-day EMAs are the most common.

The mathematical formula of MACD is as follows [2]:

$$
\text { MACD=12-daysEMA - 26-daysEMA }
$$

The mathematical formula of EMA is written as follows:

$$
\begin{aligned}
& \mathrm{EMA}_{\text {today }}=\frac{p_{1}+(1-\alpha) p_{2}+(1-\alpha)^{2} p_{3}+(1-\alpha)^{3} p_{4}+\mathrm{L}}{1+(1-\alpha)+(1-\alpha)^{2}+(1-\alpha)^{3}+\mathrm{L}} \\
& \alpha=\frac{2}{N+1} \mathrm{~N} \text { is number of periods. }
\end{aligned}
$$

Where, $p_{i}(i=1,2, \mathrm{~L} n)$ is closing price on the $\mathrm{i}^{\text {th }}$ day and $\mathrm{n}$ is number of periods in a moving average forecast. 


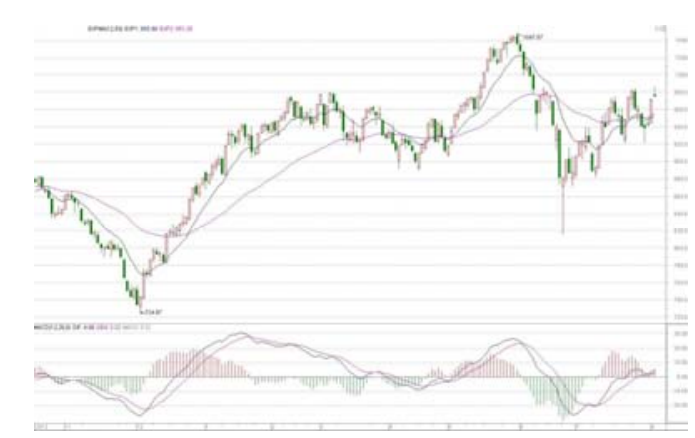

Fig 1. MACD expert system

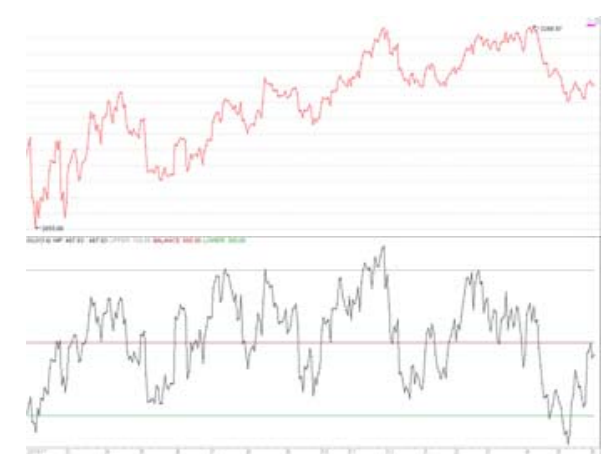

Fig 2. Shanghai Stock Exchange Indexes

\section{Empirical Analysis of MACD (Fig 1)}

Experiments and Results

(1) Experimental Procedures

MACD is based on basic practices.

Golden cross of MACD: DIFF (Differential) exceeds DEA bottom up, which suggests that stocks shall be bought.

Dead cross of MACD: DIFF goes beyond DEA in a top-down manner, which means stocks shall be sold.

MACD histogram (green to red): Negative MACD value becomes positive, and short position turns into long position in the stock market.

MACD histogram (red to green): Positive MACD value gets negative, and long position changes into short position in the stock market.

When DIFF and DEA are positive, namely they are above the neutral axis, long position will be dominant in the stock market, and stocks can be bought as long as DIFF exceeds DEA.

The short position will be dominant in the stock market and DIFF will decline beyond DEA in case that both DIFF and DEA are negative (below the neutral axis), which indicates that stocks shall be sold.

The situation will be reversed when DEA and $\mathrm{K}$ tend to deviate from each other.

Error rate will be relatively high in DEA during market correction, whereas deficiencies may be appropriately made up in combination with RSI and KDJ.

Source Codes of MACD

LONG 1020026

SHORT 220012

M 22009

DIFF: =EMA(CLOSE,SHORT) - EMA(CLOSE,LONG);

DEA : = EMA(DIFF,M);

MACD : $=2 *($ DIFF-DEA $)$;

ENTERLONG: CROSS(MACD,0);

EXITLONG: CROSS(0,MACD);

(2) Experimental platform: Great Wisdom Software (Version 5.99), Guosheng Securities

(3) Experimental parameters: close out or open a position just for once for funds that meet related standards and the trading costs shall be $0.5 \%$ of the funds.

(4) Experimental samples: daily data about cloud computing from March 2016 to April 2017.

(5) Experimental processes, time and results: 
Table1 Test Results of MACD

Test method: technical indicator - MACD

\section{Setting of System Test}

Test time: from $1^{\text {st }}$ March 2016 to $11^{\text {th }}$ April 2017, Measurements for Forced Close-out

Number of Tested Stocks: 57 Initial Investments: RMB40,000.00

Requirements for buy:

The stocks shall be bought in any of following cases:

1. All following requirements are met.

1.1. Technical indicator: DIFF of MACD $(12,26,9)$ goes upwards above the DEA (moving average)

If the above technical indicator is reached, all funds can be invested in buying stocks at average or closing price.

In case of any continuous signal, investors are not suggested to buy more.

Requirements for selling: none

Requirements for closing position: closed out at closing price

Indicator for stock selection: technical indicator: DIFF of $\operatorname{MACD}(12,26,9)$ goes downwards below the DEA

(moving average)

\section{Summary of System Test Report}

Quantity of Tested Stocks: $\quad 57$ Annual Rate of Return $\quad 19.15 \% \quad$ Trades per Year: $\quad 444.00$

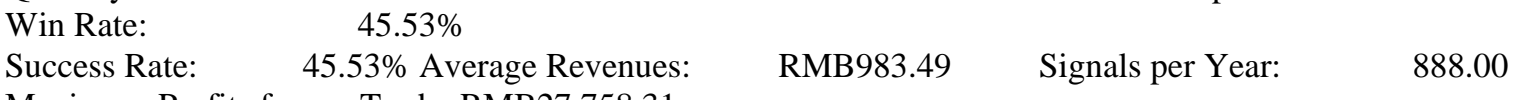
Maximum Profits from a Trade: RMB27,758.31

Maximum Losses from a Trade: RMB-8,540.42

Number of Trades: $\quad 481 \quad$ Number of Profit Trades: 219

Net Profits: $\quad$ RMB473,059.00 Net Margin: 20.75\%

Net Profits from Simple Stock Holdings: $\quad$ RMB178,446.41

Net Margin of Simple Stock Holdings: $\quad 7.83 \%$

Net Profits from Ideal Models: $\quad$ RMB27,285,252,096.00

Net Margin of Ideal Models: $\quad$ 1,196,721.63\%

\section{System Test Report}

Quantity of Tested Stocks: $\quad 57 \quad$ Net Profits: $\quad$ RMB473,059.00 Net Margin: $\quad 20.75 \%$ Total Profits: $\quad$ RMB801,934.75 Total Losses: $\quad$ RMB-328,873.34 Number of Trades: 481

Win Rate: $\quad 45.53 \%$

Average Number of Trades per Year: 444.00

Number of Trades with Profits/Losses: 219/262

Total Amount of Transactions: RMB19,470,700.00

Transaction Cost: $\quad$ RMB28,845.69

Maximum Profits from a Trade: RMB27,758.31

Maximum Losses from a Trade: $\quad$ RMB-8,540.42

$\begin{array}{lll}\text { Average Profits: } & \text { RMB1,667.22 Average Losses: } & \text { RMB-683.73 }\end{array}$

Average Revenues: RMB983.49 Average Profits/Losses: RMB-243.84

Max Number of Consecutive Profit Trades: 9

Max Number of Consecutive Trades with Losses: 8

Average Period of Trading: $\quad 14.51$

Average Period of Profit Trades: $\quad 21.44$

Average Period of Trades with Losses: $\quad 8.72$

Coefficient of Revenues: 0.42 Max Fluctuating Revenues: RMB2,714,960.25 Max Fluctuating Losses:

RMB0.00

Difference between Max Fluctuating Revenues and Losses: $\quad$ RMB2,714,960.25

Total Investments: $\quad$ RMB2,280,000.00

Statistics of Buy Signals

(All buy signals are recorded without considering signals which are eliminated in transaction tests because of funds and strategies)

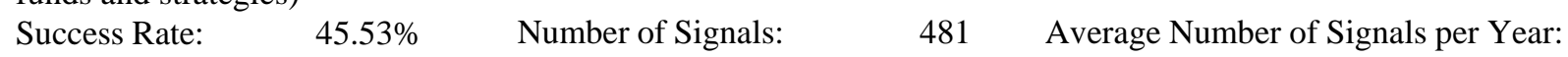
444.00 
Analysis of Results

Table2 Comparative Analysis

\begin{tabular}{|c|c|c|c|c|}
\hline & Win Rate & $\begin{array}{c}\text { Annual Rate of } \\
\text { Return }\end{array}$ & Net Margin: & $\begin{array}{c}\text { Average Number of } \\
\text { Trades per Year }\end{array}$ \\
\hline MACD & 45.53 & 19.15 & 20.75 & 444.00 \\
\hline $\begin{array}{c}\text { Shanghai Stock } \\
\text { Exchange Indexes }\end{array}$ & & 18.76 & 20.33 & \\
\hline $\begin{array}{c}\text { Ratios between MACD } \\
\text { Results and Shanghai } \\
\text { Stock Exchange Indexes }\end{array}$ & & $102.08 \%$ & $102.07 \%$ & \\
\hline
\end{tabular}

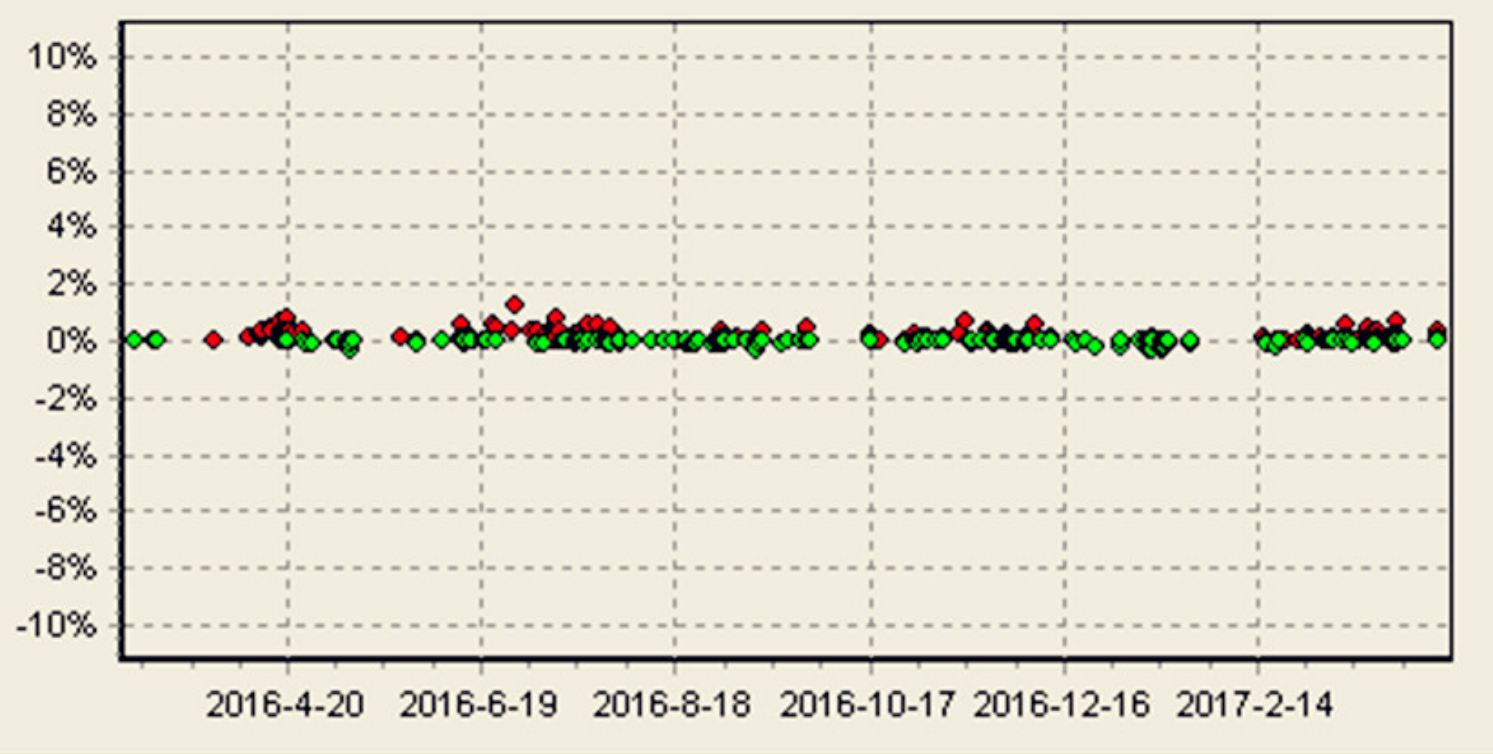

Fig 3. Average Number of Trades per Year by MACD

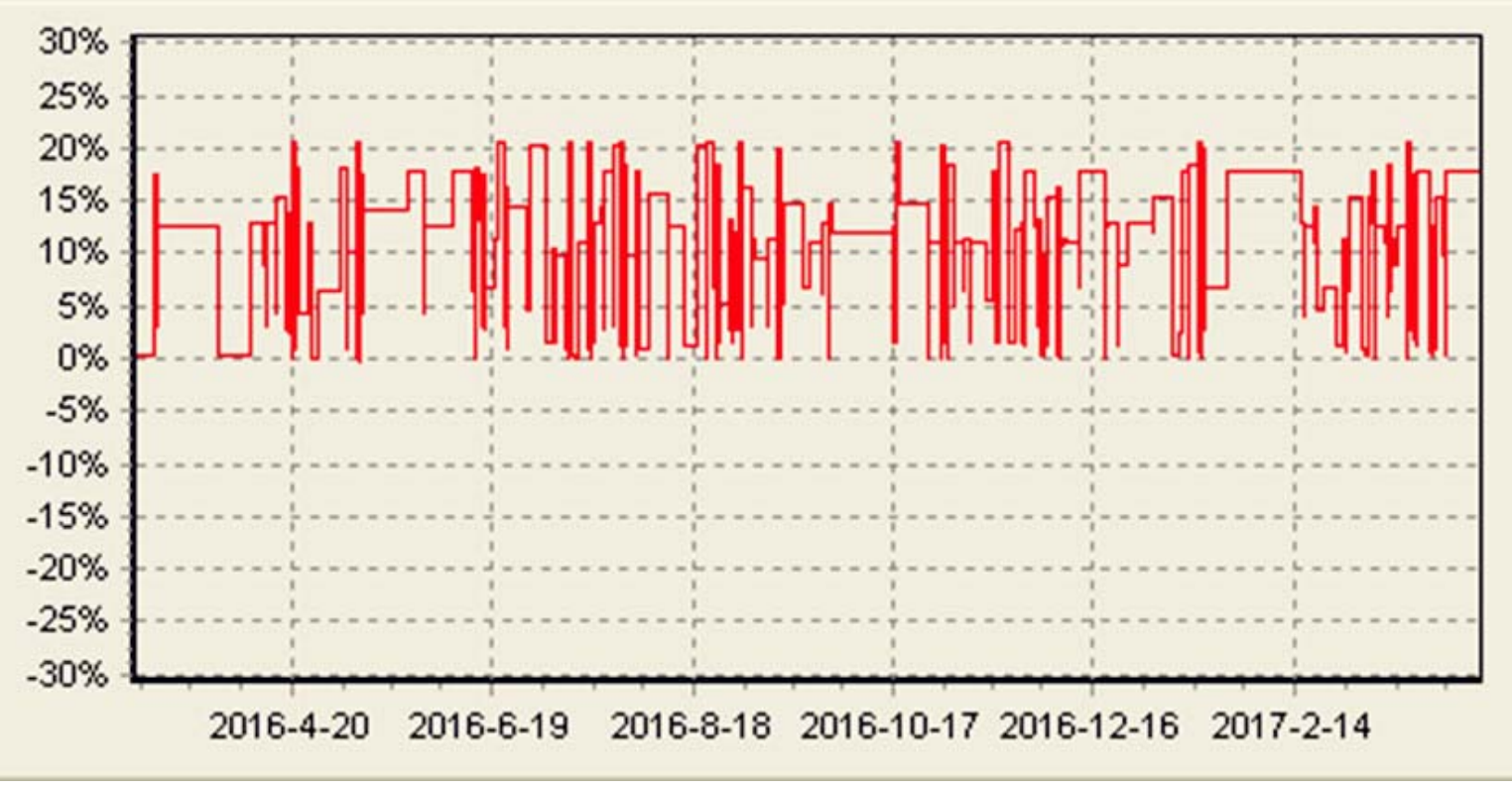

Fig 4. Yield Curve of MACD 


\section{Conclusions}

Based on management objectives of win rate, annual rate of return and net margin that investors give priority to [3-5], this paper analyzes practicality of MACD. According to the experimental results, annual rate of return and net profit margin of the MACD are $102.08 \%$ and $102.07 \%$ of Shanghai Stock Exchange indexes respectively, which suggests that it is absolutely possible to outperform benchmark indexes by guiding investments in cloud computing with MACD. The win rate of MACD is $45.53 \%$, which further reveals that investors are exposed to relatively considerable risks in this expert system. Thus, it is evident that this investment option is unpopular among risk averse investors. The annual rate of return is as high as $20.75 \%$ in MACD, which is 11.85 times of annual interest rate of bank deposits (1.75\%). Therefore, a considerable amount of revenues can be apparently earned from MACD. In a word, it is a risky option to guide investments in cloud computing with MACD. In addition, Figs 1 and 2 about MACD clearly show that frequent transactions are major causes of risks. In view that the annual rate of return on MACD is relatively high, it would be another investment option for investors who prefer making considerable profits and assuming risks.

\section{Acknowledgement}

This research was financially supported by the Education Department of Guangxi Province (NO.KY2016YB579), and scientific research projects of Guangxi College of Education in 2015 (NO.A2015001,NO.B2015001,NO.B2015006), and 2017 Key Program for Education and Teaching Reform of Guangxi College of Education (NO.XJJG17A09).

\section{References}

[1] Information on http:/wiki.mbalib.com/wiki/\%E5\%B9\%B3\%E6\%BB\%91\%E5\%BC\%82\%E5 \%90\%8C\%Е7\%A7\%BB\%E5\%8A\%A8\%Е5\%B9\%B3\%Е5\%9D\%87\%Е7\%BA\%BF

[2] Information on http://forex-indicators.net/macd

[3] Y. Liu: Empirical Study on Senior Managers and Performances in Companies of High-Tech based on SPSS Software Regression Analysis, Journal of software. 7(7)1569-1576

[4] Y. M. Wang: Application of Moving Average in Stock Market, Zhejiang Statistics(in Chinese),2 (1998)25.

[5] Y.B. Cao: Application of MACD Index in Securities Investment, Manager's Journal(in Chinese), 4(2010)166-167. 